Cancer Institute from being given autonomy. The move was partly successful because the Act was amended at a late stage in the House of Representatives to keep the cancer institute at least partly within the structure of $\mathrm{NIH}$. At that time, however, the Administration had lent its official public support to a bill which would have set up the $\mathrm{Na}$ tional Cancer Institute as virtually an independent body.

The NIH scientists, in their reply, state that "with Dr Edwards, we deplore the fragmentation of the NIH, but it is essential to recognize that this fragmentation was opposed by the NIH administration". The nub of their argument about management control of biomedical research is that "we fully appreciate the importance of political and cconomic considerations in the process by which the nation decides how much is to be spent on biomedical research. But whatever that sum may be, we believe that the nation will reap the largest benefit if scientific and medical considerations govern tho programs and administration of the NIH".

So far, thanks partly to the public airing of their grievances and support from influential members of Congress, NIH scientists have been relatively successful in their efforts to maintain at least a semblance of autonomy for the institute from management control by HEW and OMB. In the process, however, the three top officials who ran NIH during the first four years of the Nixon Administration-Robert Q. Marston, NIII Director, Robert Berliner, NIH Associate Director for Science, and Sherman-have either been forced out or have resigned to take less frustrating jobs.

\section{When is a forgery not a forgery?}

\section{John Hall}

Curiouser and curiouser, remarked at least half a dozen scholarly gentlemen who found that they had stcpped out of the grim reality of a February night in London and into the topsy-turvy realm of Vinland. Falling through the portals of the Royal Geographical Society they learned on the one hand that the renowned map of Vinland was drawn in twentieth century ink, and on the other that this did not necessarily mean that it wasn't a genuine work of fifteenth century scholarship illustrating a Norse voyage of discovery to North America.

Turning aside from the richest collection of medieval documents in the world, George Painter made his way from the British Museum's research department to Kensington Gore in order to explain that there was no mistaking the work- ings of a bona fide medieval mind in the cartography, the linguisties and the scholarship of the map which is now the property of Yale University. ("O.K. here's your hundred thousand to buy the thing", Andrew Mellon is reputed to have said, "but if it turns out a forgery, well just don't come calling for anything ever again". Right now he must feel justified in stamping his foot.)

Meanwhile, looking up from his microanalytical mass spectrometer, burly, close-cropped Walter MeCrone, of MeCrone Associates, Chicago, delivered himself of the opinion that the likelihood of a pigment of the crystalline size and shape of that found in the Vinland Map ink being used in a map of AD 1400 'could be compared with the likelihood that Admiral Nelson's flagship at Trafalgar was a hovercraft.'

Only time will tell, held Painter, how we might arrive at a scenario admitting that a fifteenth century manuscript might remain genuine in spite of its being drawn in an anatase pigment containing tilanium dioxide particles first manufactured only fifty years ago. Leaving aside time travel, the prospects for such a scenario seem to fall into three catcgorics. First, suppose somebody happened on the Vinland Map, thought its outline had become too faint for comfortable scanning, and dashed over it with modern ink. Sorry, says McCrone, but there's no sign of further pigmentation below the titanium dioxide ink.

Suppose then that an ingenious scribe, scraping about for a new line in inks, decided to use the very compound which wasn't used again for that purpose until about 1920 ? No way, says McCrone. Naturally-occurring titanium would contain impurities such as iron and manganese: what's more, the titanium dioxide used was a precipitate, the shape and size of whose particles were indistinguishable from those used in anatase.

All right, says Painter. Textual evidence indicates that the version we have is a copy of earlier versions: is it not possible then that the present version is simply one more copy, a modern one, made from a genuine version of the map, if at several removes? Not even the implacable McCrone can gainsay this possibility: it is not within the realms of spectrometry. Without any sort of material support, the thesis doesn't look al that powerful, but Painter points out that the chemical analysis of the ink is simply one piece of evidence, which has to be weighed alongside considerations such as the quality of the scholarship and the thinking embodied in the map These aspects are not quantifiable, and may seem less tangible than a scientific analysis, but they nevertheless add up to evidence, and deserve to be weighed equally with McCrone's findings.

Painter's hopes for a future recon- eiliation of the chemical evidence and the scholarly hunch is heartwarming, but it must be reported that his is a voice crying in the wilderness, and the weight of opinion seems to be that the jig is up for the map's supporters. Another of the British Museum's research team, Mr A. D. Baynes-Cope, has had his doubts for some years, and told Yale as much when they asked in 1968. The thing has been scrubbed, as if in attempt to give it a weathered look, and the worm holes in the vellum have been patched in an amatcurish way, says Baynes-Cope. The British Muscum's own craftsmen could have made a better forgery.

Scholars being what they are, nobody is prepared to say exactly who was the Vinland Map's Mr Big. The name of a European professor of canon law, one Jelic, is bandied about, but as he died in 1922, that wouldn't have left him all that much time to do the job after the introduction of anatase inks. One thing's for sure, and that is that the forger (assuming the thing was forged) didn't make a fortune out of his work. The map was sold for only 3,500 dollars as recently as the late fifties, and even McCrone is bound to admit that the effort was worth considerably more than that. His theory is that maybe some gifted academic drew the map for his private amusement, and that it only assumed importance, and cash value, when it was discovered after his death.

Either way, no real harm has been done anywhere outside the Mellon Foundation's cheque book (if they were the anonymous donors. If not, pace Andrew Mellon). Another of the British Museum's sceptics, Dr Helen Wallis, points out that at best the map would have been significant evidence that the $\mathrm{Vi}$ kings had a good working knowledge of the North American coastline fifty years before Columbus set sail. At worst it amounts to an interesting forgery which, incidentally, has prompted a work of scholarship (The Vinland Map and the Tartar Relation, by Skelton, Marston and Painter) which has turned out to be the standard work in that area of study, regardless of the map's worth.

\section{Health risk in PVC manufacture?}

THE British Factory Inspectorate has begun discussions with industry to decide what action may be necessary to protect workers from a possible health risk arising from the use of vinyl chloride monomer (an intermediate used in the manufacture of PVC). The talks follow news that an American PVC manufacturer investigating causes of death 